\title{
Clastogenic effects of different Ureaplasma urealyticum serovars on human chromosomes
}

\author{
R.A.F. Cunha ${ }^{1}$, \\ C.P. Koiffman², \\ D.H. Souza ${ }^{2}$ and \\ K. Takei ${ }^{1}$
}

\author{
${ }^{1}$ Departamento de Análises Clínicas, Faculdade de Ciências Farmacêuticas, \\ Universidade de São Paulo, 05508-900 São Paulo, SP, Brasil \\ ${ }^{2}$ Laboratório de Citogenética, Unidade de Aconselhamento Genético, \\ Departamento de Biologia, Instituto de Biociências, Universidade de São Paulo, \\ 05508-900 São Paulo, SP, Brasil
}

\section{Correspondence \\ R.A.F. Cunha \\ Departamento de Análises Clínicas \\ e Toxicológicas \\ Faculdade de Ciências Farmacêuticas \\ Universidade de São Paulo \\ Av. Lineu Prestes, 580 \\ 05508-900 São Paulo, SP \\ Brasil \\ Research supported by CNPq (No. 040-3996/90). Publication supported by FAPESP.}

Received April 30, 1996

Accepted March 18, 1997

\begin{abstract}
The possibility that Ureaplasma urealyticum might play an important role in human infertility was first raised more than 20 years ago, but this association remains speculative. Considering the hypothesis that the pathogenicity of Ureaplasma urealyticum may depend on its serotypes, the clastogenic effects of different strains of Ureaplasma urealyticum, at concentrations of $10^{3} \mathrm{CCU}$ (color changing units) $/ \mathrm{ml}$,
\end{abstract}

Key words - Mycoplasma

- Chromosome alterations - Ureaplasma urealyticum

- Clastogenic effects

\section{Introduction}

Mycoplasmas are the smallest prokaryotes able to self-replicate and their main feature is the absence of a cell wall. These two facts account for some of the distinctive characteristics peculiar to the group. Mycoplasmas are responsible for many diseases affecting animals and plants, some of them fatal. However, the role of these microorganisms in human pathologies is only partially known. The search for evidence indicative of any correlation between the presence of these microorganisms and human morbidity and mortality has been the subject of many studies.

Among the human mycoplasmas, Ureaplasma urealyticum is a common inhabitant of the urogenital tract and has been associated with non-gonococcal urethritis and chronic prostatitis with direct interference with spermatogenesis, among other diseases. The higher incidence of chorioamnionitis, premature birth, fetal loss, premature rupture 
of fetal membranes and low-weight newborns observed among women with Ureaplasma-positive placentas is evidence of the vertical transmission of the microorganism. The rate of vertical transmission ranges from $18 \%$ to $55 \%$ among full-term infants and from $29 \%$ to $55 \%$ among preterm infants. The high colonization rates in pregnancy make it difficult to validate the concept of fetal/neonatal infection based only on the isolation of Ureaplasma urealyticum. However, the possible consequences of this colonization cannot and must not be ignored in pregnant women with problems of reproductive wastage $(1,2)$.

For a long time Mycoplasmas sp have been indicated as the microorganisms responsible for many changes in eukaryotic cells with varying deleterious effects $(3,4)$. Different mycoplasma species can lead to different changes in a certain cell, while the same mycoplasma species can lead to different changes in cells of the same type belonging to different host species. Chromosomal aberrations, mitotic inhibition and stimulation and various other cytopathic effects have been observed (5-9).

The difficulties in establishing the role of Ureaplasma urealyticum in diseases of the reproductive tract and the antigenic variation among strains suggest that only some of the 14 serotypes are associated with disease (10-12).

The objective of the present study was to determine the clastogenic effects of different Ureaplasma urealyticum serotypes on human chromosomes in vitro. The understanding of these interactions may be relevant for the study of some of the diseaseinducing mechanisms of mycoplasmas.

\section{Material and Methods}

Lymphocytes were obtained from a single donor and 11 serotypes of Ureaplasma urealyticum $(1,2,3,5,6,7,8,9,10,11,12)$ were obtained from the American Type Cul- ture Collection. Four supernatants obtained by centrifugation of the culture broths of serotypes 2, 3, 7 and 10 at $14,200 g$ for 40 min were also assayed.

Strains were prepared by culturing in modified $U_{10}$ medium (13) and incubating under microaerophilic conditions for 18 to $24 \mathrm{~h} . \mathrm{A}_{7}$ solid medium (14) was used to observe the growth and viability of the microorganisms. The inocula were microtitrated in such a way that $225 \mu \mathrm{l}$ of $\mathrm{U}_{10}$ medium was added to each microtiter plate well. Twentyfive $\mu l$ of the culture medium for each serotype was added to the first well after homogenization. Successive dilutions were prepared from $25 \mu \mathrm{l}$ of this first dilution. After incubation, the highest dilution in which the microorganism grew (this growth was indicated by the change in color of the culture medium) was taken as the titer, and the results were compared with those obtained with a control $\left(\mathrm{U}_{10}\right.$ medium without the inoculum).

Lymphocyte cultures were prepared by the method of Moorhead et al. (15) with some modifications. For each assay, $20 \mathrm{ml}$ of aseptically collected venous blood was allowed to sediment by keeping the syringe in a vertical position for 2 to $3 \mathrm{~h}$. After red cell sedimentation, the supernatant was transferred to a sterile flask and homogenized and $0.5 \mathrm{ml}$ of this material was added to each flask together with $4 \mathrm{ml}$ of 199 medium supplemented with $10 \%$ fetal calf serum and Bacto phytohemagglutinin-P (Difco, cod. 3110 ) at a concentration of $125 \mu \mathrm{l} / 100 \mathrm{ml}$.

\section{Test culture}

Culture broth $(0.5 \mathrm{ml})$ from each serotype was added to the lymphocyte cultures at concentrations, expressed as $\mathrm{CCU} / \mathrm{ml}$ (color changing units $/ \mathrm{ml}$ ), of $10^{3} \mathrm{CCU} / \mathrm{ml}, 10^{4} \mathrm{CCU} /$ $\mathrm{ml}$ and $10^{5} \mathrm{CCU} / \mathrm{ml}$, and the preparations were then incubated at $36.5^{\circ} \mathrm{C}$ for $72 \mathrm{~h}$. After this period, $0.1 \mathrm{ml}$ of $4 \times 10^{-5} \mathrm{M}$ colchicine was added, and the material was incubated 
for $1 \mathrm{~h}$. The lymphocyte viability test was carried out using $1 \%$ Trypan blue.

\section{Control culture}

The procedure for lymphocyte culture was the same as that used for the test culture, except that Ureaplasma urealyticum was not added.

\section{Slide preparation}

The contents of the flasks were centrifuged at $300 \mathrm{~g}$ for $5 \mathrm{~min}$, the supernatant was discarded, $4 \mathrm{ml}$ of hypotonic solution (75 $\mathrm{mM} \mathrm{KCl}$ ) was added, and the flasks were incubated for $20 \mathrm{~min}$. After incubation and centrifugation, a few drops of fixative (methanol/acetic acid, 3:1) were added to the sediment. After homogenization, $4 \mathrm{ml}$ of fixative was added and the preparation was centrifuged again at $300 \mathrm{~g}$ for $5 \mathrm{~min}$. The supernatant was removed and the same procedure was repeated once more. Two or 3 drops of this material were then transferred to slides and stained with Giemsa in sodium phosphate buffer, pH 6.8. After staining, the slides were submitted to microscopic analysis for the determination of mitotic index and for chromosome analysis.

\section{Chromosome analysis}

Metaphases were analyzed and classified according to the presence of structural aberrations. Metaphases presenting chromosomes with structural alterations were drawn and then photographed. The mitotic index was determined by counting the metaphases obtained out of 1,000 stimulated cells. In this study we considered a mitotic index of less than 10 to indicate partial inhibition of mitosis.

The following structural chromosome abnormalities were considered: chromatid gap (chtg), chromatid breaks (chtb), chromosome break (chrb), rearrangement (rea), ring chromosome $(\mathrm{r})$, premature centromeric disjunction (pcd) and centromeric decondensation (cd) (16).

Data were analyzed statistically by the Pearson chi-square test to determine the effect of inoculum concentration on the mitotic process, and by the significance test for the difference between two population proportions, applied to determine the significance of the results obtained for the test cultures compared with the control cultures. The level of significance was set at $\alpha=5 \%$ (17).

\section{Results}

The effects of 11 serotypes of Ureaplasma urealyticum on human chromosomes were studied, together with 4 supernatants obtained from cultures of serotypes 2, 3, 7 and 10. All tests were conducted with their respective controls and the slides were analyzed in a blind test.

We studied the effects of the microorganism on mitosis and mitotic index. Among the results observed, the main feature was total and partial mitotic inhibition (mitotic indexes equal to zero and below 10, respectively). Figures 1 and 2 show the values of the mitotic indexes obtained after stimulation with 11 serotypes at concentrations of $10^{3} \mathrm{CCU} / \mathrm{ml}, 10^{4} \mathrm{CCU} / \mathrm{ml}$ and $10^{5} \mathrm{CCU} / \mathrm{ml}$ and for the supernatants from serotypes 2, 3 , 7 and 10. All control cultures were also submitted to determination of mitotic index and karyotype analysis.

Mitotic indexes equal to zero or below 10 were observed for serotypes $1,2,3,7,9,10$ and 12. Similar results were obtained for supernatants 2, 3 and 7. Some of these serotypes presented these effects only at certain microorganism concentrations: serotype 1 $\left(10^{5} \mathrm{CCU} / \mathrm{ml}\right)$, serotype $7\left(10^{3}\right.$ and $10^{5} \mathrm{CCU} /$ $\mathrm{ml})$, serotype $9\left(10^{5} \mathrm{CCU} / \mathrm{ml}\right)$, serotype 10 $\left(10^{5} \mathrm{CCU} / \mathrm{ml}\right)$ and serotype $12\left(10^{4}\right.$ and $10^{5}$ $\mathrm{CCU} / \mathrm{ml})$. Serotypes 2 and 3 caused partial mitotic inhibition regardless of their concentration (Table 1). 
Figure 1 - Reduction of human lymphocyte mitotic index by $U$. urealyticum serotypes as a function of concentration. $\mathrm{CCU} / \mathrm{ml}=$ Color changing unit/ml. $\mathbf{\square}$, Serotype; $\mathbb{\mathbb { Q }}$, control.
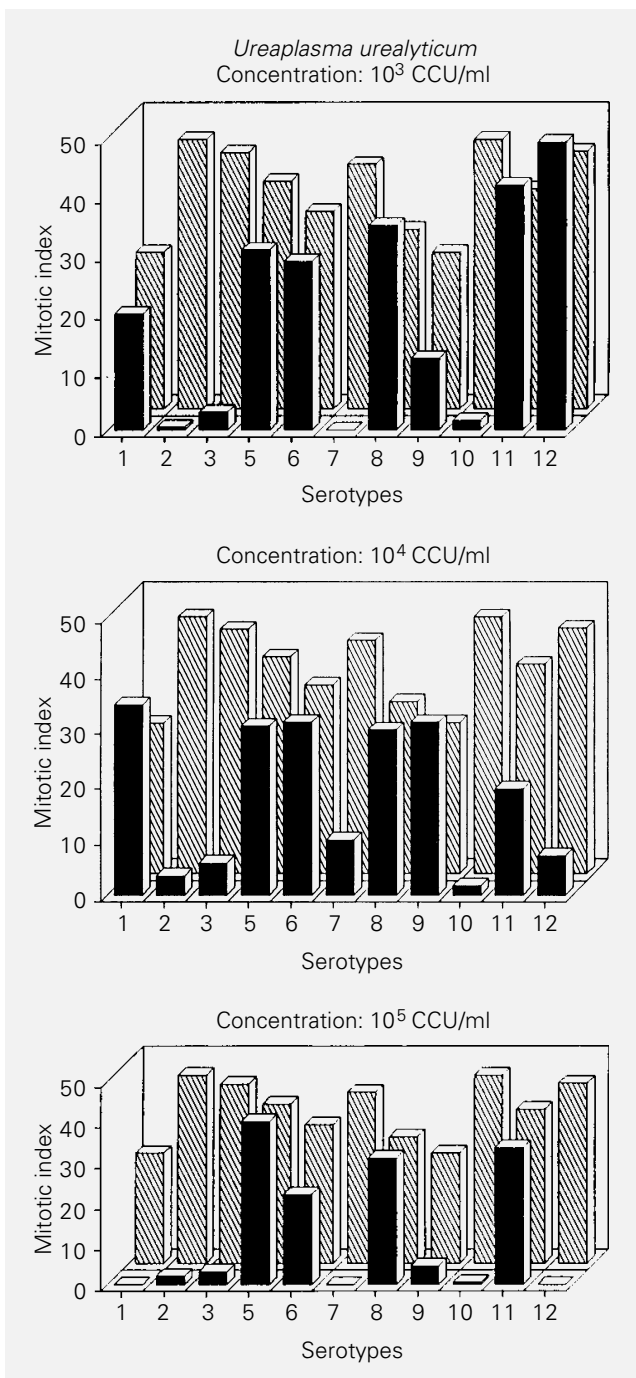

The structural chromosome alterations observed were gaps, chromatid breaks, chromosome breaks, acentric fragments, premature centromeric disjunction (partial and total), centromeric decondensation (partial and total), ring chromosomes and chromosome rearrangements. Some chromosome aberrations could not be fully explained, but the statistical significance of their incidence earned them the designation "other alterations". This designation also includes ring chromosomes and multiradial figures (Figures 3 and 4).

The Ureaplasma urealyticum serotypes and concentrations that caused structural chromosome aberrations were serotype 7 at the concentration of $10^{4} \mathrm{CCU} / \mathrm{ml}$, serotype 8 at concentrations of $10^{3}, 10^{4}, 10^{5}$ and $>10^{5}$ $\mathrm{CCU} / \mathrm{ml}$, serotype 9 at concentrations of $10^{3}$, $10^{4}$ and $10^{5} \mathrm{CCU} / \mathrm{ml}$, serotype 11 at concentrations of $10^{3}, 10^{4}$ and $10^{5} \mathrm{CCU} / \mathrm{ml}$, serotype 12 at the concentration of $10^{3} \mathrm{CCU} / \mathrm{ml}$, and the supernatants from serotypes 3 and 7 . Serotypes 5 and 6 showed chromosome aberrations at concentrations of $10^{3}$ and $10^{5}$ $\mathrm{CCU} / \mathrm{ml}$, but these results were not statistically significant when compared to the respective controls. Serotype 8 at concentrations of $10^{4}, 10^{5}$ and $>10^{5} \mathrm{CCU} / \mathrm{ml}$, serotype 9 at the concentration of $10^{3} \mathrm{CCU} / \mathrm{ml}$, serotype 11 at the concentration of $10^{5} \mathrm{CCU} / \mathrm{ml}$, serotype 12 at the concentration of $10^{3} \mathrm{CCU} /$ $\mathrm{ml}$ and the supernatants from serotypes 3 and 7 caused significantly increased alterations compared to their respective controls. Among these, gaps, chromatid breaks, chromosome breaks and partial centromeric decondensation were the most frequently observed.

The highest frequency of gaps and chromatid breaks was observed in the cultures with serotype 8 at concentrations of $10^{4}, 10^{5}$ and $>10^{5} \mathrm{CCU} / \mathrm{ml}$ and serotypes 9 and 11 at concentrations of $10^{3} \mathrm{CCU} / \mathrm{ml}$ and $10^{5} \mathrm{CCU} /$ $\mathrm{ml}$, respectively.

Chromosome breaks were significantly increased in the serotype 8 culture at concentrations of $10^{5}$ and $>10^{5} \mathrm{CCU} / \mathrm{ml}$. Partial centromeric decondensation was most frequent in serotype 8 at concentrations of $10^{4}$ and $10^{5} \mathrm{CCU} / \mathrm{ml}$ and serotype 9 at the concentration of $10^{5} \mathrm{CCU} / \mathrm{ml}$. The serotype 8 test culture at a concentration of $10^{5} \mathrm{CCU} / \mathrm{ml}$ presented metaphases with drastic multiple chromosome alterations that could not be defined and that occurred with statistical significance, thus being classified as "other" alterations.

Sixteen of the 5432 control culture metaphases analyzed presented chromosome alterations $(0.3 \%)$. The most frequent were gaps (52\%), followed by chromosome breaks (24\%) and chromatid breaks (16\%). These 
values did not differ significantly from those obtained for their respective test cultures.

A total of 101 of the 6164 test culture metaphases analyzed presented structural chromosome alterations (1.6\%). The most frequent were gaps (53\%), followed by chromatid breaks (13.9\%), partial centromeric decondensation (9.5\%), chromosome breaks (4.4\%), total centromeric decondensation $(4.4 \%)$ and "other alterations" (8.9\%).

In serotypes 5, 6, 7, 8, 9, 11 and 12 chromosome alterations only occurred at certain inoculum concentrations.

\section{Discussion}

The alterations in chromosome organization observed when the cell is exposed to mutagenic agents represent a typical and easily detectable effect. Short-term cultures of peripheral blood lymphocytes represent one of the most sensitive techniques for the in vitro detection of these effects in human genetic material (18). Yet these studies serve only as indicators, because the individual characteristics of the lymphocyte donors can alter the frequency of cells with chromosome alterations $(19,20)$. According to the literature, the average frequency of cells with chromosome alterations ranges from $1 \%$ to $20 \%$ in normal individuals (21-24). In our control group, the observed frequencies ranged from $0.2 \%$ to $2.6 \%$, which indicates that the methodology used was adequate for the experiment.

Various cell systems have been used in attempts to explain some cytopathic effects caused by mycoplasmic infection $(25,26)$. Schneider et al. (27) and Fogh and Fogh (28), in studies of the possible effects of mycoplasmas on cell cultures from amniotic fluid, showed that mycoplasmas are responsible for a significant increase in the number of chromosome alterations of these cells. Our findings demonstrated that, in vitro, different Ureaplasma urealyticum serotypes may be responsible for structural damage to

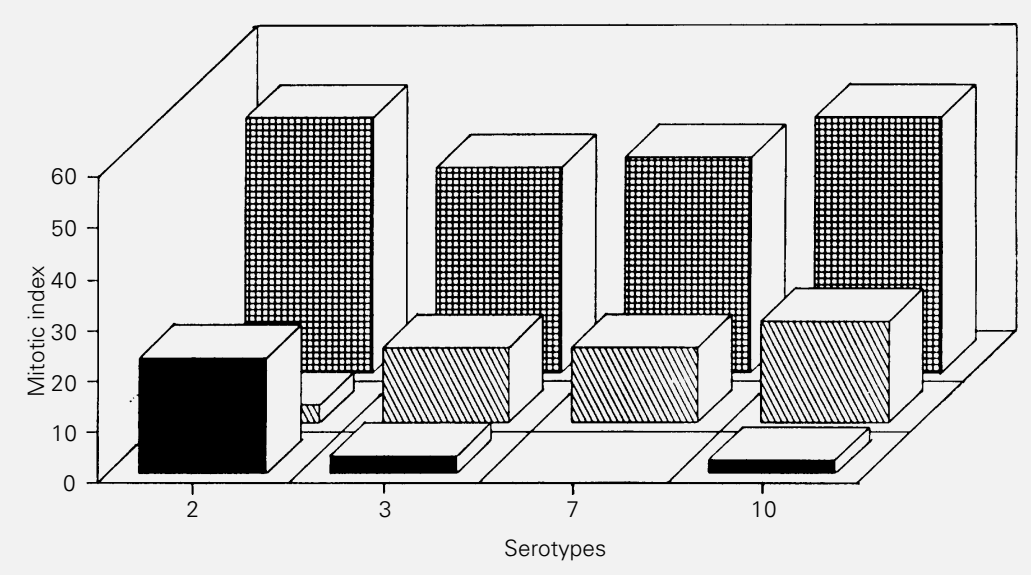

Figure 2 - Effect of supernatants of Ureaplasma urealyticum serotypes on the mitotic index of human lymphocytes in vitro. $S_{1}(\boldsymbol{\square})=$ Supernatants of serotypes $2,3,7$ and 10 at the concentration of $10^{5} \mathrm{CCU} / \mathrm{ml} ; \mathrm{S}_{2}(\mathbb{\mathbb { Q }})=$ supernatant duplicate; $\mathrm{C}_{\mathrm{s}}(\mathbf{\mathbb { B }})=$ supernatant control.

Table 1 - Effect of serotype and concentration on $U$. urealyticum-induced modifications of human lymphocyte mitosis in vitro. Concentration is reported as $\mathrm{CCU} / \mathrm{ml}$ (color changing units $/ \mathrm{ml}$.

\begin{tabular}{lcccc}
\hline $\begin{array}{l}\text { U. urealyticum } \\
\text { serotypes }\end{array}$ & $\begin{array}{c}\text { Total mitosis } \\
\text { inhibition }\end{array}$ & $\begin{array}{c}\text { Partial mitosis } \\
\text { inhibition }\end{array}$ & $\begin{array}{c}\text { Metaphases with } \\
\text { chromosome } \\
\text { alterations }\end{array}$ & $\begin{array}{c}\text { Metaphases without } \\
\text { chromosome } \\
\text { alterations }\end{array}$ \\
\hline 1 & $10^{5}$ & $10^{3}, 10^{4}, 10^{5}$ & & $10^{3}, 10^{4}$ \\
2 & & $10^{3}, 10^{4}, 10^{5}$ & \\
3 & & & $10^{3}, 10^{5}$ & $10^{4}$ \\
5 & & & $10^{3}, 10^{5}$ & $10^{4}$ \\
6 & $10^{3}, 10^{5}$ & & $10^{4}$ & \\
7 & & & $10^{3}, 10^{4}, 10^{5},>10^{5}$ & \\
8 & & $10^{5}$ & $10^{3}, 10^{4}$ & \\
9 & & $10^{3}, 10^{4}, 10^{5}$ & & \\
10 & & & $10^{3}, 10^{4}, 10^{5}$ & \\
11 & $10^{5}$ & $10^{4}$ & $10^{3}$ & \\
12 & & &
\end{tabular}

chromosomes. Thus, amniocentesis of pregnant women highly colonized by this microorganism should detect an abnormal fetal karyotype.

Many studies have been devoted to the controversial role ofUreaplasma urealyticum in perinatal pathologies. The high intraspecies antigenic heterogeneity has been responsible for the difficulties in establishing a correlation between the ureaplasmic infection and the appearance of disease. Ureaplasma urealyticum comprises 14 serotypes, 


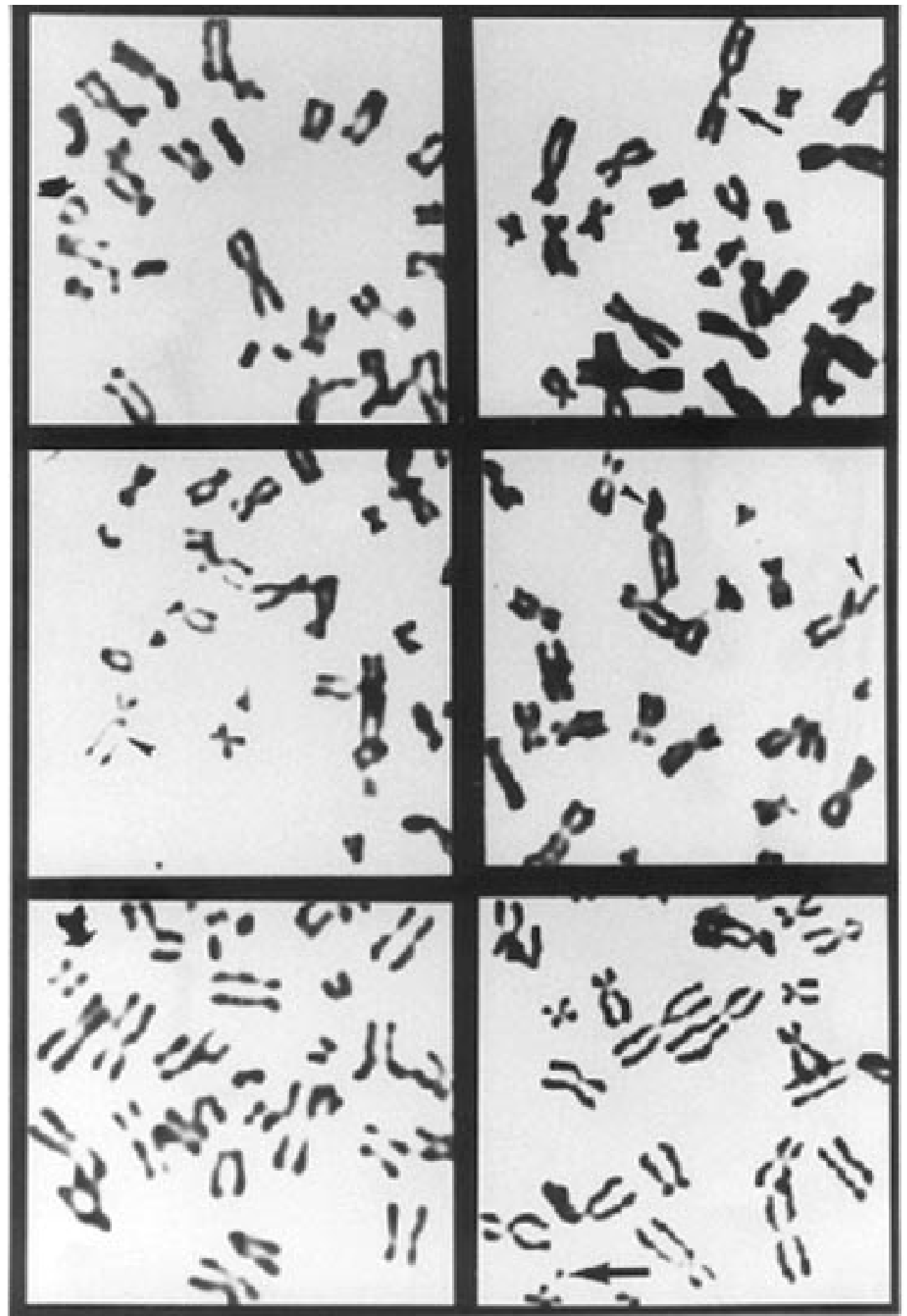

Figure 3 - Structural chromosome alterations caused by $U$. urealyticum serotypes on mitosis: ring chromosome (-): chromatid gaps $(\rightarrow)$ ); chromatid breaks ( $>$ ); partial premature centromeric disjunction (m); chromosome fragment $(\rightarrow)$. 


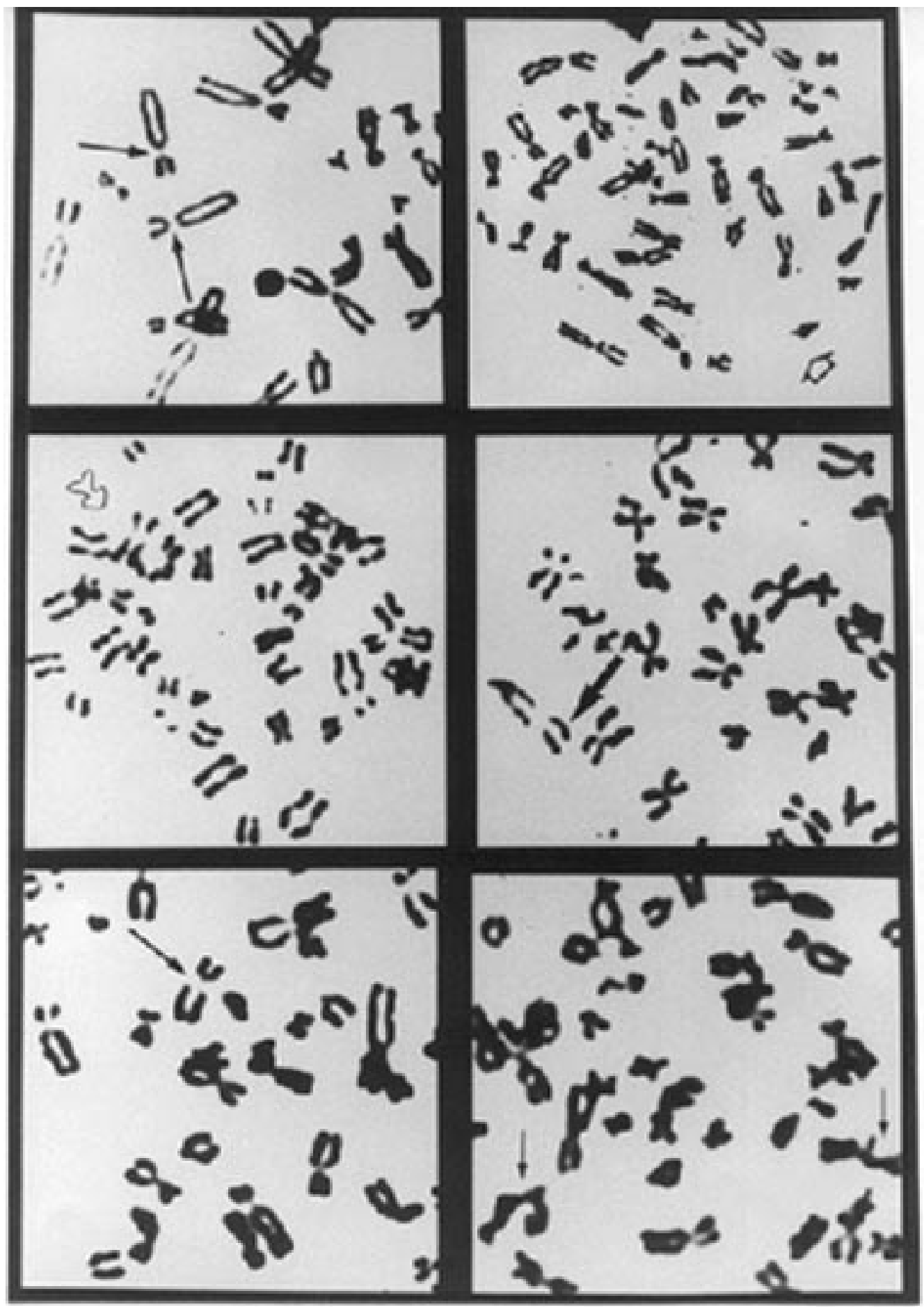

Figure 4 - Structural alterations caused by U. urealyticum serotypes: centromeric decondensation ( $\longrightarrow$ ); total centromeric premature disjunction (ED): chromosome fragment $(\longrightarrow)$; chromatid rearrangements $(\longrightarrow)$ : metaphases with several aberrations (a). 
classified into two clusters: A (serotypes 2, $4,5,7,8,9,10,11,12$ and 13) and B (serotypes 1, 3, 6 and 14). Among these, the B cluster serotypes are the most frequently involved in human pathologies, although serotypes 4 , 8 and 10 from cluster A also play an important role in some processes $(11,29,30)$.

The aim of the present study was to establish a correlation between the serotypes studied and the structural chromosome alterations observed, and to determine (on the basis of the supernatants) if soluble products produced by the strains may be responsible for these alterations. The results indicated that serotypes 1, 2, 7, 10 and 12 from cluster A and serotype 3 from cluster B were responsible for the partial or total inhibition of mitosis. Metaphases presenting morphological chromosome alterations were the main features among serotypes 8, 9, 11 and 12 from cluster A. Among these, serotype 8 presented a significantly higher frequency of these alterations. In addition, the supernatants of serotypes 3 and 7 showed reduction in the mitotic index and clastogenic effects, both possibly caused by ammonia release. Consequently, we observed that serotypes from both clusters had clastogenic effects on human chromosomes and on the mitotic process itself. Our results are consistent with the clinical analysis of some investigators who correlated positive cases of Ureaplasma urealyticum with the involvement of serotypes 3,8 and 10 (12,29-32).

The isolation of mycoplasma from human malignant tissues reported by some investigators and the effects on human chromosomes demonstrated here suggest the importance of further studies on the role of these microorganisms in certain carcinogenic processes (33-35).

\section{Acknowledgments}

We would like to thank Carlos Malheiros, Difco Laboratories, for kindly providing the serotypes of Ureaplasma urealyticum, Suely Nonogaki for excellent technical assistance, and Prof. Dr. Ana Campa and Prof. Dr. Adelaide José Vaz for revising the text

\section{References}

1. Cunha RAF, Takimoto S \& Takei K (1988). Micoplasmas: Isolamento e identificação em material cervical de gestantes. Revista de Microbiologia, 19: 379-384.

2. Kundsin RB, Driscoll SG \& Ming PML (1967). Strain of mycoplasma associated with human reproductive failure. Science, 157: 1573-1574

3. McGarrity GJ, Phillips DM \& Vaydya $A B$ (1990). Mycoplasmal infection of lymphocyte cell cultures: Infection with Mycoplasma salivarium. In Vitro, 16: 346-356.

4. Ruth E \& Praz F (1989). Interactions between mycoplasmas and the immune system. Immunological Reviews, 112: 133160.

5. Aula P \& Nichole W (1967). The cytogenetic effect of mycoplasma in human leukocyte cultures. Journal of Cellular Physiology, 70: 281-290.

6. Cooperman R \& Morton HE (1966). Reversible inhibition of mitosis in lymphocyte cultures by non-viable mycoplasma. Proceedings of the Society for Experimental Biology and Medicine, 123: 790-795.
7. Ginsburg H \& Nicolet J (1973). Extensive transformation of lymphocytes by a mycoplasma organism. Nature, 246: 143146.

8. Naot $Y \&$ Ginsburg H (1978). Activation of B lymphocytes by mycoplasma mitogen. Immunology, 34: 715-720.

9. Naot $Y$ (1982). In vitro studies on the mitogenic activity of mycoplasmal species toward lymphocytes. Reviews of Infectious Diseases, 4: 205-209.

10. Quinn PA, Arshoff LV \& Li HCS (1981). Serotyping of Ureaplasma urealyticum by immunoperoxidase assay. Journal of Clinical Microbiology, 13: 670-676.

11. Razin S \& Yogeu D (1986). Genetic relatedness among Ureaplasma urealyticum (serovars). Pediatric Infectious Diseases, 5: 300-304.

12. Robertson JA, Honoré LH, Kakulphimip J, Hill GB \& Jenkins HJ (1990). Association of Ureaplasma urealyticum with spontaneous abortion. In: Inums Congress Bacteriology \& Mycology. Osaka, 156 (Abstract).
13. Shepard MC (1974). Standard fluid medium $\mathrm{U}_{10}$ for cultivation and maintenance of Ureaplasma urealyticum. International Journal of Systematic Bacteriology, 24: 160-171.

14. Shepard MC \& Lunceford CD (1976). Differential agar medium $\left(A_{7}\right)$ for identification of Ureaplasma urealyticum I (human T-mycoplasma) in primary cultures of clinical material. Journal of Clinical Microbiology, 3: 625-631.

15. Moorhead PS, Noweel PC, Melmann WJ Battips DM \& Hungerford DA (1960). Chromosome preparations of leukocytes cultured from peripheral blood. Experimental Cell Research, 20: 613-616.

16. ISCN (1995). An International System for Human Cytogenetic Nomenclature. Mitelman F (Editor). S. Karger, Basel, 2729.

17. Sounis E (1985). Introdução à teoria da decisão estatística. In: Bioestatística. Atheneu, São Paulo, 207-234. 
18. Richardson CR, Howard CA, Sheldon T, Wildgoose J \& Thomas MG (1984). The human lymphocyte in vitro cytogenetic assay: positive and negative control observations on approximately 30,000 cells. Mutation Research, 141: 59-64.

19. Evans HJ \& O'Riordan ML (1975). Human peripheral blood lymphocytes for the analysis of chromosome aberrations in mutagen tests. Mutation Research, 31: 135-148.

20. Matter BE (1976). Problems of testing drugs for potential mutagenicity. Mutation Research, 38: 243-258.

21. Gundy S \& Varga LP (1983). Chromosomal aberrations in healthy persons. Mutation Research, 120: 187-191.

22. Littlefield GL \& Goh KO (1973). Cytogenetic studies in control men and women. Cytogenetics and Cell Genetics, 12: 1734.

23. Lubs HA \& Samuelson J (1967). Chromosome abnormalities in lymphocytes from normal human subjects. Cytogenetics, 6 : 402-411.

24. Mattei MG, Ayme S, Mattei JF, Aurran Y \& Giraud F (1979). Distribution of spontaneous chromosome breaks in man. Cytogenetics and Cell Genetics, 23: 95-102.
25. Stalheim OHV, Proctor SJ \& Gallagher JE (1976). Growth and effects of Ureaplasma urealyticum (T-mycoplasma) in bovine oviductal organ cultures. Infection and Immunity, 13: 915-925.

26. Taylor-Robinson D \& Carney FG (1974). Growth and effect of mycoplasmas in FalIopian tube organ cultures. British Journal of Venereal Diseases, 50: 212-216.

27. Schneider E, Stanbridge EJ \& Golbus CJE (1974). Mycoplasma contamination of cultured amniotic fluid cells: Potential hazard to prenatal chromosomal diagnosis. Science, 184: 477-479.

28. Fogh J \& Fogh H (1968). Karyotypic changes in mycoplasma modified lines of 11 human amnion cells. Proceedings of the Society for Experimental Biology and Medicine, 129: 944-950.

29. Robertson JA, Honoré LH \& Stemke GW (1986). Serotypes of Ureaplasma urealyticum in spontaneous abortion. Pediatric Infectious Diseases, 5: 270 -272.

30. Zheng X, Watson HL, Waites KB \& Cassel $\mathrm{GH}$ (1992). Serotype diversity and antigen variation among invasive isolates of Ureaplasma urealyticum from neonates. Infection and Immunity, 60: 3472-3474.
31. Cracea E, Botez DC \& Braila SMG (1984) Ureaplasma urealyticum serotypes isolated from cases of female sterility. Yale Journal of Biology and Medicine, 57: 895.

32. Naessens A, Foulon W, Breynaert J \& Lauers S (1988). Serotypes of Ureaplasma urealyticum isolated from normal pregnant women and patients with pregnancy complications. Journal of Clinical Microbiology, 26: 319-322.

33. Barile MF (1967). Mycoplasma and leukemia. Annals of the New York Academy of Sciences, 143: 557-563.

34. Jansson E \& Wager O (1967). Mycoplasma in collagen diseases and blood dyscrasia. Annals of the New York Academy of Sciences, 143: 535-543.

35. Murfy WH, Bullis C, Ertel IJ \& Zarafonetis JD (1967). Mycoplasma studies of human leukemia. Annals of the New York Academy of Sciences, 143: 544-556. 